TAs: IV. - Shewing the percentage of Admiesions and Doaths to Strength for the different periods, as above.

\begin{tabular}{|c|c|c|}
\hline & $\begin{array}{l}\text { Admissions to } \\
\text { Strength. }\end{array}$ & $\begin{array}{l}\text { Deaths to } \\
\text { Strength. }\end{array}$ \\
\hline $\begin{array}{l}\text {-For Six Months after Land. } \\
\text { ing, } 1854 \ldots \ldots \ldots \ldots \ldots \\
\text { +For Isast Quarter of } 1855 \ldots \\
\text { fFor January } 1856 \ldots \ldots \ldots \text {. }\end{array}$ & $\begin{array}{r}100 \cdot 86 \\
33 \cdot 6.3 \\
7.65\end{array}$ & $\begin{array}{c}15.87 \\
0 \cdot 81 \\
0.2\end{array}$ \\
\hline
\end{tabular}

Rxunkx.-The difference of period should be borne in mind.

\section{CASES IN MIDWIFERY.}

By Thoxas Raprond, M.D., F.R.C.P.Edin., etc., Consulting Physician to St. Mary's Hospital, Manchester.

\section{[Continued from page 105.]}

Case xv. March 11th, 1824. Early in the morning, Mr. Dadley desired me to visit a hospital patient living in Miller's Lane, to whom he had been called by Mrs. Frost. She was in labour of her seventh child. Mr. Dadley found her very much reduced from hæmorrhage, which had continued for some time previously to his being sent for, and which now recurred with greater violence during the pains, which were frequent and short. The os uteri was low down in the pelvis, soft, and dilated to about the size of a half-crown. He discovered a portion of the placenta with the membranes, and higher up, the head of the child. At this time a messenger was dispatched for me; but before I arrived, she was dead. Mr. Dadley stated the symptoms of exhaustion became so urgent, that he felt he should not be justified in waiting for me, and therefore he determined on immediate delivery. He passed his hand by the side of the placenta, and then ruptured the membranes: the patient immediately fainted and died.

Permission was obtained for a post mortem examination. The aspect of the body was white and exsanguined. The abdominal viscera were pale. The uterus was flaccid and large in size; on cutting through its parietes, they were found thinner than usual. The placenta was also thin, and extensively connected to the right side of the cervix and body of the womb. The os uteri was nearly fully opened, and within it there was a narrow loosened portion of placenta.

Rexarks. Although I did not see the patient during her life, there can be no doubt the vital powers were very greatly exhausted from the hæmorrhage, which had been incessant for a very considerable length of time.

The case is an example of an opposite character to some of those which are already cited. The atonic state of the uterus, evinced by the very feeble pains, and further proved by the post mortem examination, no doubt mainly contributed to the fatal issue. If the fundus and body had acted energetically at an early period of the labour, the os uteri being so soft and unresistant, it is most probable the woman would have been saved under judicious obstetric management.

CABE xvI. April 25th, 1825. Through the kindness of my colleague Mr. Fawdington, I was present at the post mortem examination of a hospital patient. I was told she had lost a very large quantity of blood, which did not escape by large impetuous gushes, which sometimes immediately destroy a woman, but by an incessant dribbling discharge. $\Delta s$ her dissolution seemed impending, it was deemed right to deliver her, although the os uteri was high, felt rigid, and was very little dilated. Mr. Fawdington stated that he performed the operation very slowly and carefully, but with great difficulty. The child was stillborn. She died on the second day after her delivery.

On inspecting the body, it was white and exsanguine. There was a little watery fluid in the peritoneal carity. The uterus was soft and larger than usual. The os was ragged, there being several lacerations through its tissue, which appeared as if it was gangrenous.

CASE XVIr. March 11th, 1830. Farly in the morning, Mrs. - midwife, sent for me to see a patient, whom the messenger stated to be in labour, and in great danger. She was in the eighth month of her sixth pregnanc. She had flooded, more or less constantly, for a fortnight. Her labour began the evening before, and she had strong pains during the whole of the night, which were accompanied by an increased discharge of blood. She was very much exhausted. Her countenance was extremely pale. The surface of the body felt very cold. Her pulse was scarcely perceptible. There was great restlessness, and she gasped for breath. The os uteri was soft, and dilated to about the size of a dollar. A portion of the placenta protruded through it into the vagina. As her death was inevitable, I deemed it right only to tighten the bandage, which was already about her, and to pass a piece of sponge per vaginam, more for the sake of satisfaction to her friends than to serve any other purpose. Brandy and water, etc., were ordered, but she bad difficulty in swallowing. She died in about an hour.

Consent was obtained to examine the body the day following. It was white, as if altogether drained of blood. There was extreme paleness observable in the abdominal viscera. On cutting into the uterus, and opening the membranes, some liquor amnii escaped. The child lay in a natural position, and its body was very white, as if it had also lost its blood. The placenta was remarkably thin, and extensively connected; it covered the os, the cervix, and the body of the womb; it was more like a placental bag than like (as it is usually called) "a cake". That portion of this organ into which the funis was inserted was placed nearly over the centre of the os uteri. This opening was soft and considerably dilated, and was filled with the placenta, which was lacerated, and its tissue loaded with coagulated blood.

REMARRs. The midwife was most unpardonable in allowing this poor creature to bleed to death without earlier sending for further assistance. What individual efforts she might have ignorantly made to save the woman, I am unable to state; although I strongly suspect she (the midwife) had rudely meddled with the placenta. The extensive connexion of this organ tended, no doubt, to increase the hazards which usually belong to a central position of it over the os uteri. An early and judicious delivery wonld have afforded her the best, and indeed the only, chance of being saved. The whiteness of the child's body shewed that its blood had drained away; and there is no doubt that the source from whence it escaped was the lacesated placental tissue. (Vide Lancet, loc. cit.)

CASE xvirr. June 23rd, 1847. I received a note from Mr. Dunn, requesting me to see Mrs. L., who was flooding, in consultation with him, and to bring my galvanic apparatus along with me. He stated to me that she was now in labour of her fifth child, and had previously two attacks of slight hæmorrhage, both of which had been arrested by quietude, cold applications, and an acid mixture. She was delicate leucophlegmatic woman, about 40 years of age.

When Mr. Dunn first saw her, she had felt trifling pains; and the discharge, which at first was only moderate, gradually increased. There was no obvious cause to account for either this or the two former attacks. The os uteri was thin and partially dilated. The membranes and a portion of the placenta were felt, and a little above, the head of the child presented. An abdominal bandage had been applied, and cold water and vinegar externally used. As the pains continued to come on very frequently, and were very weak, and the hæmorrhage was much greater, I was now sent for. I found this lady very feeble, evidently suffering the effects of loss of blood. Her countenance was pallid, especially the lips. The skin was pale; the pulse frequent and small; the os uteri was soft and thin, and dilated as nearly as possible to the size of a crown-piece. The pains seemed 
very weak and ineffective, and indeed the membranes were vers dightly affected during their continuance; a considecable sized portion of placents was felt in connexion with them.

On applying $m y$ hand on the abdomen during the contraction of the uterus, I ascertained that this organ did not then bocome hard and resistant, but it continued softish. Under these circumstances, we concluded first to pass the glvanic currents through the longitudinal and transverse axis of the uterus; and afterwards to adopt such measures as we thought best suitable for the case. After a very short time the uterus acted more energetically. The regulating bandage was now put on, and afterwards the hand was introduced, and a portion of the placenta was detached, and the membranes were ruptured. The waters being discharged, the head very soon came down, and pressed on the os uteri. The hrmorrhage had now entirely cessed. Although the pains were much stronger, we considered it prudent to again pass the galvanic current through the uterus; and we continued to do so at intervals for about an hour. During this time the pains strengthened; and the head of the child descended and passed by the placenta, pressing this organ against the side of the pelvis. The child was born (alive) in about three hours after we first applied galvanism. The placenta was re moved from the vagina in half an hour, and there was only an ordinary discharge of blood.

BExAkKs. An atonic state of the uterus in cases of unaroidable hæmorrhage is always to be deplored, for although the placenta is always more or less separated by each pain, yet active contraction of the fundus and body of the uterus, especially when there coexists a dilated and a dilatable os, is most advantageous, and tends, under proper obstetric management, to save the woman. The os w2s in this farourable condition, and by the application of galvanism, active and effective, uterine contraction was induced. The salutary effects of this powerful agent are not confined alone to giving energy to the uterus; but the depressed vital powers are raised by its use.

CaSE XIX. April 13th, 1848. I saw a poor woman residing in Canal Street, along with my respected friend and late pupil, Mr. Dorrington. She was in labour of her seventh child. He said he found her flooding excessively; the os uteri very little dilated and firm. The midwife informed him the patient had flooded very slightly twice before. Each of these attacks had come on without any assignable cause. The pains were regular, but very short and weak. Mr. Dorrington had a bandage, with a compress under it, tightly applied. He ordered her a drachm of laudanum. He remained with the patient for some time; and then, as there was no hæmorrhage, he left, and in about three to four hours he called again to see her; and as there was no further discharge of blood, and as there was an improvement in her pulse, and the pains still were frequent and feeble, he determined to withdraw the plug. Some small coagula with the liquor amnii immediately came away, and soon afterwards fresh blood flowed. Mr. Dorrington found the os uteri considerably dilated, and rery soft, and he now felt a portion of the placenta, and through the opened membranes he touched the head of the child. At this time I was sent for, and requested to bring my galvanic apparatus. She appeared to have lost a large quantity of blood; she was very pale; her pulse was frequent and small; and she was faintish. I passed the hand and found the os uteri dilated to a considerable size and dilatable, and a portion of placenta loosely hanging through it. With Mr. Dorrington's concurrence, I further detached this organ before withdrawing my hand.

The galvanic apparatus having during this time been got in readiness, the conductors were successively applied on the abdomen, so that the current would pass transversely and longitudinally through the uterus. One conductor was also placed on the spine, and the other on the lower portion of the body of the womb, with the view of transmitting the galvanic current along the course of the nerves. We were well satisfied with the effects of each trial. Uterine action soon improved, and in half an how was rery effeetire. The head of the child was pushed through the os uteri, forcing the placents aside. The hæmorrhage had now ceased, and as the pains returned spontaneously, the labour was left to be finished by nature. The child was born alive in about three hours from our first essay with galvanism. The placents was soon expelled. There was no more discharge than uoual. The patient recovered well.

REMARKS. The plug proved of great utility, as there is not much doubt the hæmorrhage would have been much greater than it was, and not unlikely would have been fatal, if this mode of treatment had not in the first instance been adopted. The spontaneous rupture of the membranes did not arrest or even abate the discharge. The continuance of the bleeding was in some degree owing to the atonic state of the uterus, and in some degree to leaving the placenta to have its connexions gradually broken. This organ was placed in a position favourable for the escape of blood, in consequence of the want of active uterine contraction, which would have quickly separated a necessary portion of the placenta by the head passing rapidly through the os uteri. These two important desiderata were obtained by artificially detaching a portion of the placenta, and the induction of brisk uterine contraction by the aid of galvanism.

\section{[To be continued.]}

\section{TIIE TREATMENT OF SCARLATINA ANGINOSA.}

By Pre H. Chavasse, F.R.C.S., late President of Queen's College Medico-Chirurgical Society, Birmingham.

$$
\text { [Reaul befure the Society, March 4th, 1856.] }
$$

$\Delta s$ I have been very fortunate in my cases of scarlet fever, I consider it a duty to bring my treatment before the notice of the members of this Society.

My plan, of late years, has been so uniformly successful (not having lost a case of scarlet ferer for upwards of seren years), that I have not deemed it necessary to keep a rocord of cases. The system I adopt, in a case of scarlet fever, is to keep the bedroom cool-I may say cold-and to have a thorough ventilation through it: $I$, therefore, throw open the windows, be it winter or summer, and have the curtains and valances of the bed removed. If it be winter time, I allow the patient to have one blanket and a sheet; if it be summer time, a sheet only to cover him. If the throat be not seriously affected, I merely order a narrow strip of flannel once round the throat. If the tonsils be much enlarged, I apply a barm and oatmeal poultice to the throat, changing it night and morning. I prescribe an acidulated infusion of roses mixture, that is to say, infusion of roses, with an excess of acid made palatable with an additional quantity of syrup, to be taken every three or four hours. This is the only medicine I give. Where the child is old enough, I find roasted apples, mixed with raw sugar, very grateful to the patient.

Here let me pause, to advise my medical brethren always to make medicines for children pleasant. The administration of nauseous medicine to children oftentimes causes sickness, disgust, and irritation, which frequently do mare harm than the medicine does good.

But to ruturn to our subject: I avoid purgatives in scarlet fever. I never, on any account whatever, give a particle of opening medicine for the first ten days at least. It is my firm conviction, that the administration of purgatives in scarlet fever is a fruitful source of dropsy, disease, and death. When we take into consideration the sympathy that there is between the skin and mucous membranes, I think thet we should pause before giving irritating medicines. The irritation of purgatives on the mucous membrane may cause the poison of the sluin disease to be driven internally, to the kidneys, throat, pericardium, or brain. You may ay, Do you not purge if the bowels be not opened for a woek? I say emphatically, No! 